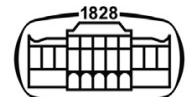

AKADÉMIAI KIADÓ

\title{
Controlling the failure behavior of FRP-reinforced concrete elements
}

\author{
Aziz Sakr ${ }^{1,2 *}$ (1) and Zoltán Orbán ${ }^{3,4}$
}

\section{Pollack Periodica \\ An International Journal \\ for Engineering and Information Sciences}

16 (2021) 1, 38-44

DOI:

$10.1556 / 606.2020 .00168$

(c) 2020 The Author(s)
ORIGINAL RESEARCH PAPER

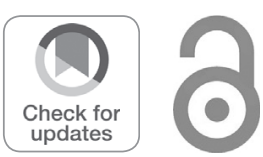

*Corresponding author

E-mail: aziz.sakr@grabarics.hu, aziz.i.sakr@hotmail.com

\author{
${ }^{1}$ Grabarics Építőipari Kft, Grabarics Vasbeton üzem, Major u. 32, 3360 Heves, Hungary \\ 2 Department of Civil Engineering, Faculty of Engineering and Information Technology, University \\ of Pécs, Boszorkány u. 2, 7624 Pécs, Hungary \\ ${ }^{3}$ Department of Civil Engineering, Institute of Smart Technology and Engineering, Faculty of \\ Engineering and Information Technology, University of Pécs, Boszorkány u. 2, 7624 Pécs, Hungary \\ ${ }^{4}$ Structural Diagnostics and Analysis Research Group, University of Pécs, Boszorkány u. 2, 7624 Pécs, \\ Hungary
}

Received: December 31, 2019 • Revised manuscript received: May 29, 2020 • Accepted: June 12, 2020

Published online: February 24, 2021

\section{ABSTRACT}

Concrete indeterminate flexural members represented by continuous beams reinforced with both fiberreinforced polymers and steel bars in a way that allows for moment redistribution at failure are analyzed. The efficiency of introducing steel bars in the critical sections where plastic hinges are likely to form is evaluated in terms of reliability. Monte Carlo simulation and the concept of comparative reliability are both employed. Ultimately, the effect of different design parameters on the strength reduction factor is evaluated.

\section{KEYWORDS}

fiber reinforced polymers, moment redistribution, failure control, reliability index, strength reduction factor, flexural moment capacity

\section{INTRODUCTION AND LITERATURE REVIEW}

The use of Fiber-Reinforced Polymers (FRP) reinforcing bars in concrete structures is becoming more desirable as an alternative for steel reinforcement. The noncorrosive properties and the high strength-to-weight ratio of FRP reinforcement provide a perfect solution for optimized structures in aggressive environments. However, a drawback is its low modulus of elasticity compared to steel which results in early concrete cracking at lower service loads [1], as well as the lack of failure ductility in the flexural elements. Therefore, in order to compensate for the sudden failure of FRP-reinforced elements, very conservative safety factors - compared to those used for steel reinforced sections - are adopted in the design process. A strength reduction factor ranging between 0.55 and 0.65 according to the failure mode is recommended by the ACI 440.1R-06 Standard [2]. Similarly, the fib-bulletin 40 [3] recommends the use of a partial safety factor for FRP bars of 1.3 instead of the 1.15 factor recommended for steel reinforcement.

Regarding the enhancements of ductility of FRP-reinforced members, many researchers focused on improvements in the compression zone. One study suggested the use of ductile materials in the compression zone of critical sections at which the plastic hinge is likely to form as a way to improve the ductility of FRP-reinforced elements [4]. Another approach was to increase the confinement of concrete in critical sections with additional stirrups as an improvement for the concrete compression ductility [5]. Other researchers recommended the addition of polypropylene fibers to the concrete mix to improve the ductility of FRP reinforced elements [6]. The most effective results were achieved by the use of hybrid reinforcement bars consisting of a steel core surrounded by multi-layers of FRP materials [7]. 
However, the use of these hybrid bars is associated to high manufacturing costs and, in case of using bars with more than one FRP layer, a gradual irreversible failure in the reinforced element due to the rupture of FRP layers. Another technique is to use additional steel bars in the FRPreinforced elements to provide some ductility in the tensile zone [8]. The latter authors recommended designing flexural elements in a way that ensures the failure is initiated by steel yielding, followed by concrete crushing and finally by the rupture of FRP bars. These elements are proposed to be designed as over-reinforced elements with the amount of FRP reinforcement more than that of steel reinforcement.

\section{ANALYTICAL INVESTIGATION}

\subsection{The analyzed case}

The suggested approach for the continuous beam reinforcement is shown in Fig. 1. The addition of steel bars over supports in a continuous FRP reinforced concrete beam will cause a significant variation in the flexural stiffness between the hogging areas (over-supports) and the sagging areas (midspans).

The following analysis is based on the static moment distribution in indeterminate beams when the flexural stiffness in hogging area is different from that in sagging area. This variation will influence the distribution of moments along the beam.

The ratio of flexural stiffness between hogging and sagging areas will affect the length of hogging area (referred to as $x$ later in the text), which is defined as the distance between the point of contra-flexure and the support. This relationship can be found by the application of the conjugate beam method. Similarly, the ratio of sagging and hogging moments is also related to the length of the hogging area, and the corresponding relationship can simply be found by the application of the force method and simple statics. Ultimately, the direct relationship between the stiffness ratio and the moment ratio can be plotted by comparing the two previously mentioned relationships.

For this analysis, it is assumed that the effect of any bars in the compression zone at any section on the flexural stiffness is neglected.
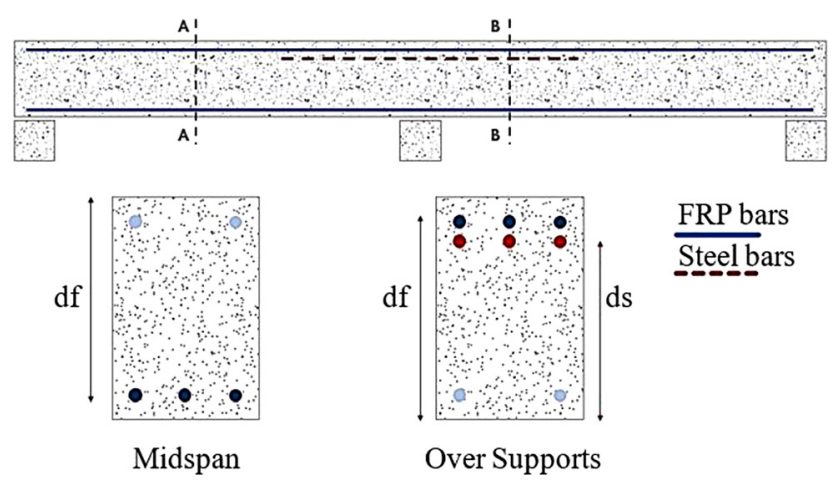

FRP bars Steel bars

Fig. 1. The suggested approach for continuous beams

\subsection{Analytical models for materials}

The stress-strain model for the behavior of concrete used in this study is divided into two parts, Fig. 2. The ascending part up to the compressive strength complies with Eq. (1) given by Saenz [9] while the descending part up to crushing is represented by Smith and Young [10] model which is given in Eq. (2).

$$
\begin{gathered}
\sigma_{c}=\frac{E_{o} \varepsilon_{c}}{1+\left(\frac{E_{0}}{E_{s c}}-2\right)\left(\frac{\varepsilon_{c}}{\varepsilon_{\max }}\right)\left(\frac{\varepsilon_{c}}{\varepsilon_{\max }}\right)^{2}}, \\
\sigma_{c}=f_{c}^{\prime}\left(\frac{\varepsilon_{c}}{\varepsilon_{\max }}\right) e^{\left(1-\frac{\varepsilon_{c}}{\varepsilon_{\max }}\right)}, \\
E_{0}=4700 \sqrt{f_{c}^{\prime}}, \\
E_{s c}=\frac{f_{c}^{\prime}}{\varepsilon_{\max }} .
\end{gathered}
$$

The FRP bars are assumed to act elastically up to rupture. Perfect bond is assumed between FRP bars and concrete throughout the loading.

The steel reinforcement used is assumed to have elastic behavior up to yielding at an elasticity modulus of $200 \mathrm{GPa}$. After yielding, the steel reinforcement is assumed to exhibit a strain hardening phase up to failure at a rate of $5 \%$ of its original modulus of elasticity. Perfect bond is also assumed between steel bars and concrete throughout the loading.

\subsection{Moment-curvature relationship}

A MATLAB code was written to calculate the stresses and the bending moment capacity in a concrete section reinforced with both steel and FRP bars using the above constitutive models for materials. Stresses are calculated at a concrete strain step of 0.00005 .

The resulting moment-curvature graph consists of three main phases: first, the section acts elastically up to steel yielding, and then it exhibits another linear-elastic behavior at a lower flexural stiffness governed mainly by the FRP modulus of elasticity up to the rupture of FRP bars. Finally, the yielded steel can still provide capacity governed by its hardening modulus. Typical moment-curvature relationships

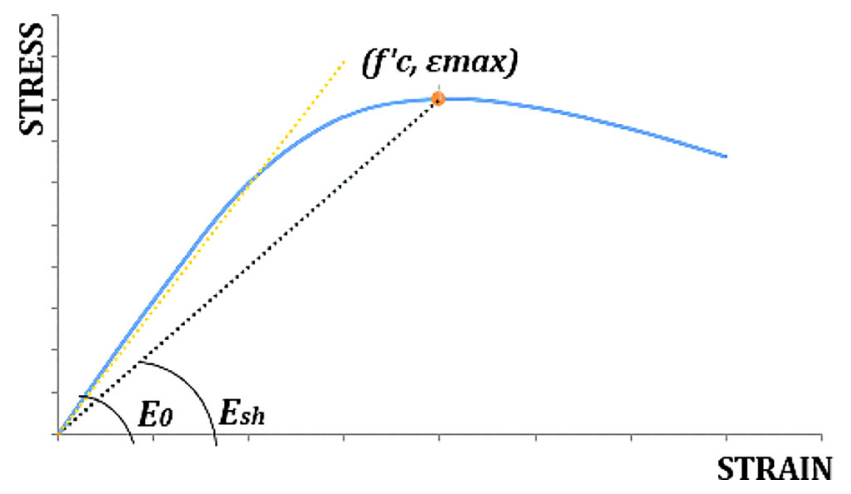

Fig. 2. The concrete model 
for sections reinforced with steel, FRP and both are shown in Fig. 3.

\subsection{Moment ratio vs. stiffness ratio}

Four cases were investigated, Fig. 4.

The relationship between moment ratio and stiffness ratio was investigated for all four cases. However, case III was chosen to illustrate the procedure.

By applying the force method at the point of contraflexure where zero moment is applicable, the following can be derived from the free body diagram in Fig. 5 .

$$
\begin{gathered}
M_{h}=\frac{P x}{2}, \\
M_{s}=\frac{P l}{4}-M_{h}, \\
\frac{M_{s}}{M_{h}}=\frac{1}{2 \alpha}-1 ; \alpha=\frac{x}{L} .
\end{gathered}
$$

By applying the conjugate beam method, and making use of the boundary condition regarding zero rotation at one end, the following can be formulated:

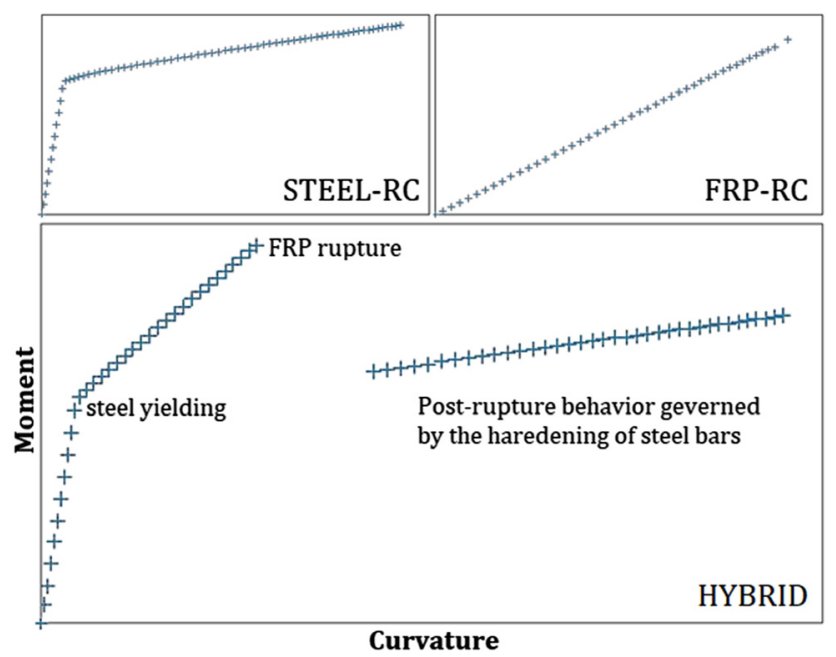

Fig. 3. Moment-curvature relationship for different reinforced concrete sections

$$
\frac{E I_{s}}{E I_{h}}=\frac{(1-2 \alpha)^{2}}{4 \alpha^{2}}
$$

Now, the relationship between the stiffness ratio and the moment ratio is plotted for each cases and the resulting graph is shown in Fig. 6. These curves will help in tracking the changes in moment distribution in an indeterminate beam with different reinforcement types in the hogging and sagging areas.

\subsection{Moment redistribution}

The investigated beams are indeterminate single-span concrete beams reinforced with FRP bars in the midspan and with FRP and steel bars over-supports.

The moment trend in hogging and sagging areas was analyzed under increasing static loading. An example of the resulting diagrams is shown in Fig. 7.

It can be seen that up to steel yielding, the hogging moment is higher than the sagging moment because it has a considerably higher stiffness resulting from the existence of steel bars. However, after yielding, the two lines start to converge.

For the following analysis a 6-m long concrete beam of case III with rectangular section was used with the design parameters presented in Table 1.

\section{RELIABILITY ANALYSIS}

\subsection{The analysis methodology}

The reliability index at hogging FRP rupture in terms of moment capacity was investigated using Monte Carlo simulation.

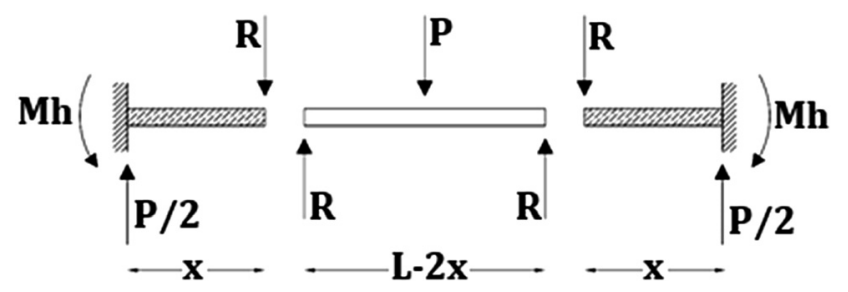

Fig. 5. Free body diagram of beam in case III
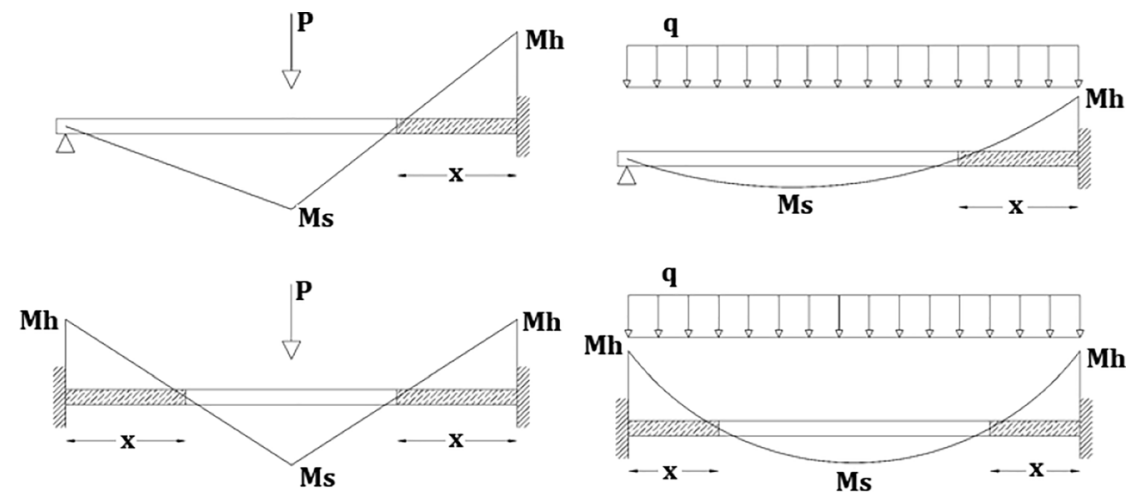

Fig. 4. The analyzed beams 


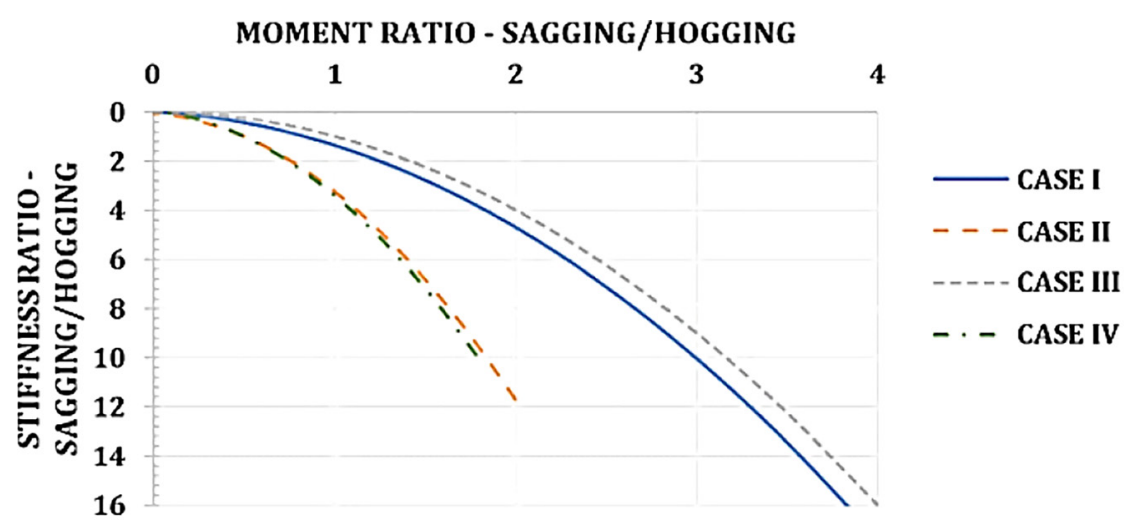

Fig. 6. Resulting relationships between stiffness ratio and moment ratio for the analyzed cases

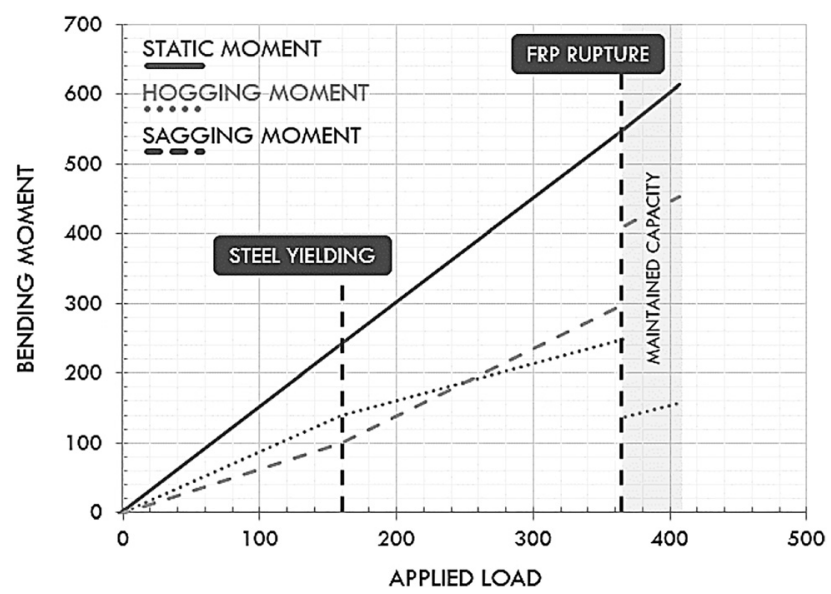

Fig. 7. Typical resulting diagram for the moment trend in hogging and sagging areas

The formula for Load and Resistance Factor Design (LRFD) design is given in Eq. (9) for a simple combination of only dead and live loads,

$$
S_{d}=\gamma_{D} D+\gamma_{L} L \leq \phi R_{n}=R_{d} .
$$

The values of mechanical, geometrical and loading parameters are considered random variables with lognormal distribution to suppress negative values. Statistical properties of all the variables used in the simulation are presented in Table 2.

The design capacity in terms of static moment is calculated for every simulated element with a preset value of $\phi$. The statistical parameters of capacity are then determined. The design loading is taken equal to the design capacity and analyzed into dead and live loads according to the loading ratio. The statistical parameters of the overall effect are then estimated and the reliability index is calculated using Eq. (10),

$$
\beta=\frac{\mu_{R}-\mu_{E}}{\sqrt{\sigma_{R}^{2}+\sigma_{E}^{2}}} .
$$

Values for the loading ratio as given in Eq. (11) were chosen in the range between 0.3 and 0.7 as suggested by Szerszen and Nowak [13] and Bojórquez and Ruiz [15],

$$
r=\frac{D}{D+L}
$$

As recommended by Szerszen and Nowak [13], the following two load combinations were used: $1.2 D+1.6 L$, $1.4 D+1.4 L$.

To validate the results, the concept of comparative reliability introduced by Zadeh and Nanni [15] was used. The comparative reliability method calibrates the strength reduction factor for design of new sections based on a comparison with another section which is well-known in the literature using a load-free formula. The calibration formula for sections with coefficients of variation less than 0.3 is given in Eq. (12) [16],

The statistical parameters for the flexural strength of a steel-reinforced concrete section are given by Nowak and Szerszen [14] and are presented in Table 3,

$$
\frac{\ln \left(\frac{\phi_{1}}{\phi_{2}} \frac{\lambda_{2}}{\lambda_{1}}\right)}{\sqrt{\delta_{1}^{2}+\delta_{2}^{2}}}=\frac{\delta_{2}-\delta_{1}}{\delta_{1}+\delta_{2}} \beta_{T} .
$$

\subsection{Strength reduction factor}

The hogging moment consists of two components: steel component $M_{\text {steel }}$ and FRP component $M_{\text {FRP. The effect of }}$ additional steel on the strength reduction factor was monitored. Sections with different steel-to-FRP ratios were simulated and the corresponding strength reduction factors were calculated using Eq. (12). For the purpose of comparison, the statistical parameters of the overall resistance were also calculated using the values given in literature for the flexural resistance of FRP-RC and steel-RC sections given in Table 3.

The following formulas were used to calculate the statistical parameters of the overall flexural resistance, normal distributions were assumed,

$$
M_{\text {Composite }}=M_{F R P}+M_{\text {steel }} .
$$

The mean value can be calculated as the sum of means by introducing the bias factors of every component: 
Table 1. Input parameters for the analyzed beams

\begin{tabular}{|c|c|c|c|c|c|c|c|}
\hline & $\begin{array}{c}d_{s} \\
\mathrm{~mm}\end{array}$ & $\begin{array}{l}A_{f, h} \\
\mathrm{~mm}^{2}\end{array}$ & $\begin{array}{c}A_{s, h} \\
\mathrm{~mm}^{2}\end{array}$ & $\begin{array}{c}A_{f, s} \\
\mathrm{~mm}^{2}\end{array}$ & $\begin{array}{c}f_{c}^{\prime} \\
\mathrm{MPa}\end{array}$ & $\begin{array}{c}f_{y} \\
\mathrm{MPa}\end{array}$ & $\begin{array}{c}f_{f u} \\
\mathrm{MPa}\end{array}$ \\
\hline $\min$ & 350 & 250 & 600 & 1,100 & 40 & 360 & 600 \\
\hline step & 50 & 75 & 100 & 150 & 5 & 90 & 100 \\
\hline $\max$ & 450 & 400 & 800 & 1,400 & 50 & 540 & 800 \\
\hline
\end{tabular}

$b=300 \mathrm{~mm}, d_{f, h}=d_{f, s}=450 \mathrm{~mm}, E_{s}=200 \mathrm{GPa}, E_{s h}=10 \mathrm{GPa}, E_{f}=40 \mathrm{GPa}$

Table 2. Statistical parameters for the reliability analysis

\begin{tabular}{llllc}
\hline & \multicolumn{1}{c}{$\lambda$} & \multicolumn{1}{c}{$\delta$} & Distribution & Reference \\
\hline$b$ & 1.01 & 0.04 & Lognormal & Nowak and Szerszen [11] \\
$d_{f}$ & 0.99 & 0.04 & Lognormal & Nowak and Szerszen [11] \\
$d_{s}$ & 0.99 & 0.04 & Lognormal & Nowak and Szerszen [11] \\
$f_{c}^{\prime}$ & 1.24 & 0.1 & Lognormal & Nowak and Szerszen [11] \\
$A_{f}$ & 1.0 & 0.03 & Lognormal & Gulbrandsen [12] \\
$A_{s}$ & 1.0 & 0.03 & Lognormal & Gulbrandsen [12] \\
$f_{f u}$ & 1.2 & 0.08 & Lognormal & Gulbrandsen [12] \\
$E_{f}$ & 1.04 & 0.08 & Lognormal & Gulbrandsen [12] \\
$E_{s}$ & 1.0 & 0.015 & Lognormal & Nowak and Szerszen [11] \\
$f_{y}$ & 1.145 & 0.05 & Lognormal & Nowak and Szerszen [11] \\
$D$ & 1.05 & 0.1 & Lognormal & Nowak and Szerszen [13] \\
$L$ & 1 & 0.18 & Lognormal & Nowak and Szerszen [13] \\
$P_{f}$ & 1 & 0.06 & Lognormal & Zadeh and Nanni [14] \\
$P_{s}$ & 1.02 & 0.06 & Lognormal & Nowak and Szerszen [11] \\
\hline
\end{tabular}

Table 3. Input and resulting reduction factor of the comparative reliability analysis

\begin{tabular}{lccccc}
\hline & $\lambda$ & $\delta$ & $\beta$ & $\varphi$ & Reference \\
\hline Steel-RC & 1.19 & 0.089 & 3.5 & 0.9 & Nowak and Szerszen [11] \\
FRP-RC & 1.11 & 0.157 & 3.5 & 0.65 & Gulbrandsen [12] \\
\hline
\end{tabular}

$$
\mu_{\text {Composite }}=\lambda_{F R P} M_{F R P}+\lambda_{\text {steel }} M_{\text {steel }} \text {. }
$$

The bias factor of the overall resistance can be then calculated:

$$
\lambda_{\text {Composite }}=\frac{\mu_{\text {Composite }}}{M_{\text {Composite }}}=\frac{\lambda_{F R P} M_{F R P}+\lambda_{\text {steel }} M_{\text {steel }}}{M_{F R P}+M_{\text {steel }}} .
$$

The standard deviation of the overall flexural resistance is calculated as the standard deviation of the sum of two normal distributions:

$$
\begin{aligned}
\sigma_{\text {Composite }} & =\sqrt{\sigma_{F R P}^{2}+\sigma_{\text {steel }}^{2}} \\
& =\sqrt{\delta_{F R P}^{2} \lambda_{F R P}^{2} M_{F R P}^{2}+\delta_{\text {steel }}^{2} \lambda_{\text {steel }}^{2} M_{\text {steel }}^{2}} .
\end{aligned}
$$

Finally, the coefficient of variation can be calculated:

$$
\delta_{\text {Composite }}=\frac{\sigma_{\text {Composite }}}{\mu_{\text {Composite }}}=\frac{\sqrt{\delta_{F R P}^{2} \lambda_{F R P}^{2} M_{F R P}^{2}+\delta_{\text {steel }}^{2} \lambda_{\text {steel }}^{2} M_{\text {steel }}^{2}}}{\lambda_{F R P} M_{F R P}+\lambda_{\text {steel }} M_{\text {steel }}} .
$$

Now, the values of $\lambda_{\text {Composite }}$ and $\delta_{\text {Composite }}$ can be substituted in Eq. (12) to find the corresponding value of strength reduction factor.
The values of the flexural strength statistical parameters as well as reduction factor resulting from both the simulation of the hogging moment and the calculations using Eqs (13)-(17) are presented in Figs 8-10 at different steel-toFRP moment ratios.

\subsection{The effect of design parameters on the reduction factor}

The condition for moment redistribution to take place as discussed in the previous sections can be translated into the following inequality where $M_{\text {static,rup }}$ is the moment capacity at hogging FRP rupture and $M_{\text {static,u }}$ is the capacity at ultimate failure:

$$
M_{\text {static, rup }}<M_{\text {static, } u} .
$$

Only 596 out of 2,187 cases as shown in Table 1 seemed to maintain flexural moment capacity after the FRP rupture

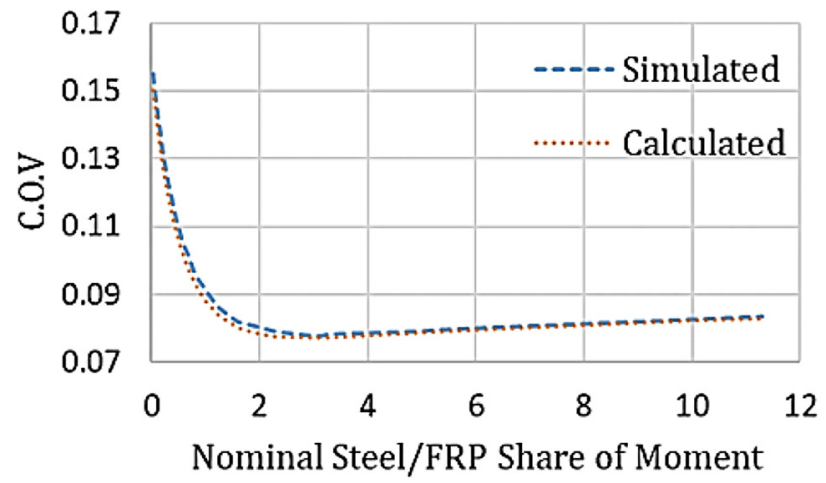

Fig. 8. COV for flexural resistance of RC section with composite reinforcement

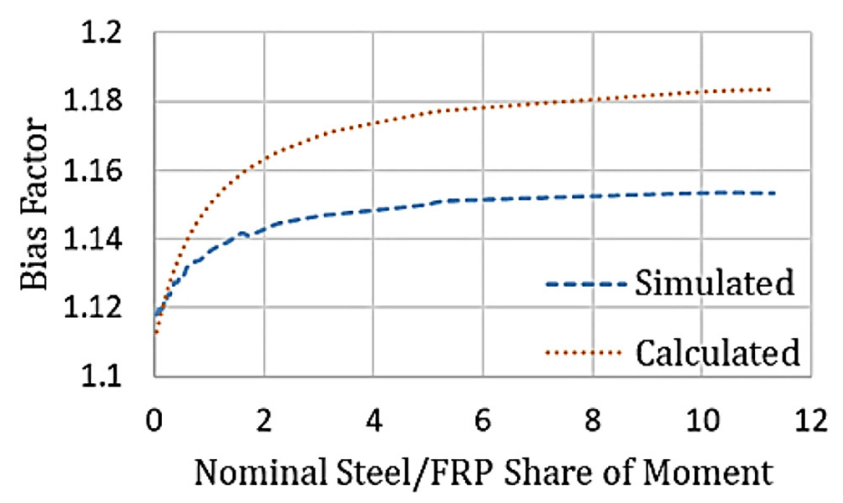

Fig. 9. Bias factor for flexural resistance of RC section with composite reinforcement 


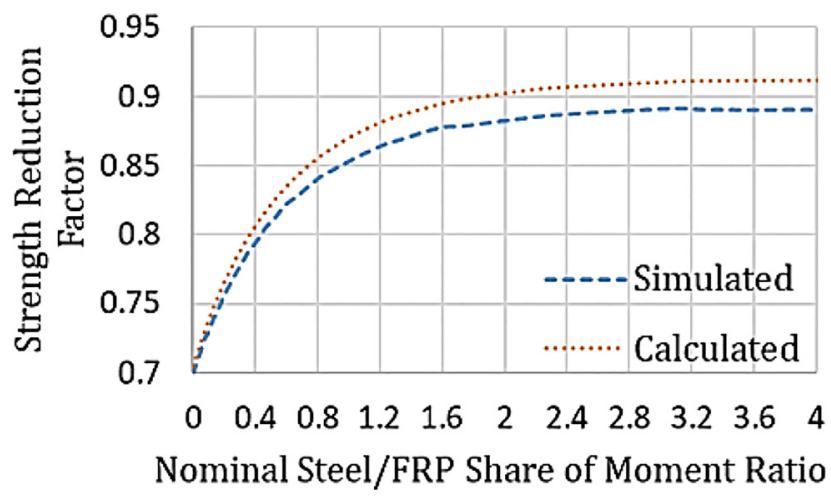

Fig. 10. SRD for flexural resistance of RC section with composite reinforcement

Table 4. Preliminary regression analysis results

\begin{tabular}{lccccc}
\hline Variable & Count & Coefficient & Mean & S. D & $\begin{array}{c}\text { Std. } \\
\text { Coeff. }\end{array}$ \\
\hline Const. & 596 & 0.77739860 & - & - & 0.0000 \\
$d_{\text {ratio }}$ & 596 & 0.04429247 & 0.8448918 & 0.0815544 & 0.4036 \\
$A_{\text {ratio_h }}$ & 596 & 0.01281244 & 2.4978580 & 0.4506196 & 0.6451 \\
$A_{\text {ratio_s }}$ & 596 & 0.00074899 & 4.8023360 & 0.6515202 & 0.0545 \\
$f_{\text {ratio_y }}$ & 596 & 0.03554251 & 0.6646003 & 0.1307895 & 0.5194 \\
$f_{\text {ratio_c }}$ & 596 & 0.30732450 & 0.0692159 & 0.0083021 & 0.0285 \\
\hline
\end{tabular}

over supports. For every case, the recommended strength reduction factor was determined based on the relationship shown in Figs 8-10. For the cases exhibiting moment redistribution, the values of $\phi$ ranged between 0.836 and 0.893 , while for the other cases a minimum value of 0.7 was considered regardless of the calculated one. The curvature ductility index scored values between 1.6 and 3.6 calculated between the point of hogging FRP rupture and the point of ultimate failure.

In order to estimate the effect of the design parameters on the strength reduction factor and define the most significant ones, a preliminary multiple regression analysis was carried out on the previous results using NCSS software. The following five ratios defined the independent variables:

$$
\begin{aligned}
& A_{\text {ratio_h }}=\frac{A_{s, h}}{A_{f, h}}, A_{\text {ratio_s }}=\frac{A_{f, s}}{A_{f, h}}, d_{\text {ratio }}=\frac{d_{s}}{d_{f, h}}, \\
& f_{\text {ratio_y }}=\frac{f_{y}}{f_{f u}}, f_{\text {ratio_c } c}=\frac{f_{c}^{\prime}}{f_{f u}} .
\end{aligned}
$$

The previous ratios replaced the original design parameters in order to eliminate the units and make the results more convenient for comparison.

Table 4 shows the significant effect of the ratios related to components of steel share of moment capacity: steel area, yielding strength and effective depth.

\section{CONCLUSION}

The use of FRP bars as reinforcement for concrete structures can be made more reliable through controlling their failure by adding a specific amount of steel bars buried inside the FRP cage in the critical sections, where plastic hinges are likely to form and adjusting the FRP reinforcement in the other sections to make them capable of taking over the additional moment redistributed from these hinges.

The suggested design approach depends on finding a balance between the flexural capacity of the designed element and the safety margin maintained at failure. This is achieved by adjusting the area of FRP and steel reinforcement along the beam.

The strength reduction factors currently recommended by the codes for FRP-reinforced elements can be significantly improved where the approach discussed in this paper is adopted. A value not lower than 0.8 can be achieved from the strength reduction factor, where sufficient moment redistribution is proven to take place at failure.

\section{ACKNOWLEDGMENTS}

The research project is conducted at the University of Pécs, Hungary, within the framework of the Biomedical Engineering Project of the Thematic Excellence Programme 2019 (TUDFO/51757-1/2019-ITM).

\section{REFERENCES}

[1] C. Krasniqi, N. Kabashi, E. Krasniqi, and V. Kaqi, "Comparison of the behavior of GFRP reinforced concrete beams with conventional steel bars," Pollack Period., vol. 13, no. 3, pp. 141-150, 2018.

[2] ACI 440.1R-06, "Guide for the design and construction of structural concrete reinforced with FRP bars," Am. Concr. Inst., 2006.

[3] "FRP reinforcement in CR structures," CEB-FIP Technical Report, FIB Bulletin, No. 40, 2007.

[4] Y. F. Wu, "New avenue of achieving ductility for reinforced concrete members," J. Struct. Eng., vol. 132, no. 9, pp. 1502-1506, 2006.

[5] B. Matos, J. R. Correia, L. M. S. Castro, and P. França, "Structural response of hyper-static concrete beams reinforced with GFRP bars: Effect of increasing concrete confinement," Compos. Struct., vol. 94 , no. 3, pp. 1200-1210, 2012.

[6] H. Wang and A. Belarbi, "Ductility characteristics of fiber-reinforced-concrete beams reinforced with FRP rebars," Constr. Build. Mater., vol. 25, no. 5, pp. 2391-2401, 2011.

[7] Y. S. Yoon, J. M. Yang, K. H. Min, and H. O. Shin, "Flexural strength and deflection characteristics of high-strength concrete beams with hybrid FRP and steel bar reinforcement," Int. Concr. Abstr. Portal, vol. 275, pp. 1-22, 2011.

[8] D. Lau and H. J. Pam, "Experimental study of hybrid FRP reinforced concrete beams," Eng. Struct., vol. 32, no. 12, pp. 38573865, 2010.

[9] L. P. Saenz, "Equation for the stress-strain curve of concrete in uniaxial and biaxial compression of concrete," ACI J., vol. 61, no. 9, pp. 1229-1235, 1965.

[10] G. M. Smith and L. E. Young, "Ultimate theory in flexure by exponential function," J. Am. Concr. Inst., vol. 52, no. 3, pp. 349359, 1955. 
[11] A. S. Nowak and M. M. Szerszen, "Calibration of design code for buildings, (ACI 318): Part 1, statistical models for resistance," Int. Concr. Abstr. Portal, vol. 100, no. 3, pp. 377-382, 2003.

[12] P. Gulbrandsen, "Reliability analysis of the flexural capacity of fiber reinforced polymer bars in concrete beams," MSc Thesis, University of Minnesota, Minneapolis, 2005.

[13] M. M. Szerszen and A. S. Nowak, "Calibration of design code for buildings, (ACI 318): Part 2, reliability analysis and resistance factors," Int. Concr. Abstr. Portal, vol. 100, no. 3, pp. 383-391, 2003.
[14] H. J. Zadeh, F. Mejia, and A. Nanni, "Strength reduction factor for flexural RC members strengthened with near-surface-mounted bars," J. Compos. Construct., vol. 17, no. 5, pp. 614-625, 2013.

[15] J. Bojórquez and S. E. Ruiz, "An efficient approach to obtain optimal load factors for structural design," Sci. World J., vol. 2014, Paper no. 456826, 2014.

[16] H. J. Zadeh and A. Nanni, "Reliability analysis of concrete beams internally reinforced with fiber-reinforced polymer bars," Int. Concr. Abstr. Portal, vol. 110, no. 6, pp. 1023-1031, 2013. 